\title{
Contemporary Information Technology and the Sustainable Development of China's Manufacturing Industry
}

\author{
Lin Kong ${ }^{1, *}$

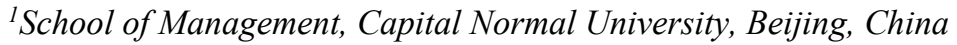 \\ *Lin Kong. Email: lin15aa@163.com
}

\begin{abstract}
A new round of global manufacturing technology revolution is emerging, China's industrial transformation is also facing a severe test, and the upgrading of China's manufacturing industry also intersects with it. The sustainable advancement and development of China's manufacturing industry to the middle and high end of the global value chains requires further acceleration of the transformation process of manufacturing informatization. Through the in-depth integration of information technology and manufacturing industry, China's manufacturing industry will be promoted to improve quality and efficiency and achieve high-quality development.

This paper analyzes the informatization of China's contemporary manufacturing industry, discusses the role of information technology in the sustainable development of China's manufacturing industry, then analyzes the problems of information technology in promoting the sustainable development of China's manufacturing industry in detail, and finally proposes the countermeasures for information technology to propel sustainable development of manufacturing industry.
\end{abstract}

Keywords: Manufacturing industry, Information technology, Sustainable development.

\section{INTRODUCTION}

Manufacturing industry is the top priority for a country to boost the real economy and stimulate economic and innovation vitality. After many years of efforts, China's manufacturing industry has made great progress, but it is still far from being a manufacturing powerhouse. The innovative integration of the Internet and the manufacturing industry can significantly improve the production efficiency of the traditional manufacturing industry and achieve a sustainable and substantial breakthrough in the real economy.

In order to optimize the business of the manufacturing industry and the application of advanced manufacturing models as the basic, manufacturing informationization is the general use of database and Internet technology to effectively manage the information of all production and processing activities of the manufacturing industry, and thus realize the effective use and sharing of internal and external information of the industry. At the same time, it also combines automation technology, manufacturing technology, information technology and modern management technology, so as to organize a new set of business management methods, find new product design methods, explore new cooperation between enterprises. These manufacturing information systems play important roles in solving some of the local business, while also increasing the efficiency of the enterprise.

\section{INFORMATIZATION OF CHINA'S CONTEMPORARY MANUFACTURING INDUSTRY}

\subsection{The application level of information manufacturing technology}

At present, only a few manufacturing industries in China apply intelligent manufacturing. Most of the manufacturing industries still use traditional technology and traditional processing means, and most of the manufacturing industry is in the budding state of big data development. The high complexity of the manufacturing process makes the application of big data in the manufacturing industry face more difficulties. Due to the large and complex manufacturing industry 
system, the equipment and processes used in different industries vary greatly, and the corresponding data acquisition is also very difficult. The amount of data in large-scale manufacturing industry puts forward higher requirements for data storage and transmission. The weak awareness of manufacturing enterprises on the application of data resources results in unsound planning and matching.

\subsection{Some manufacturing enterprises have started to shift from mass production mode to on-demand production mode}

Nowadays, with the continuous upgrading of information technology, some manufacturing industries have started to explore the possibility of transforming from mass production to on-demand customized production mode, effectively using new information technology, new Internet technology, and on-demand production through data analysis to provide users with the whole process of personalized experience.

On-demand production is to make full use of low-cost processing and higher production efficiency to provide products to meet different needs of different consumers. By changing the production and processing process, using some new materials from advanced excavation and modern information management concepts, it organically combines the needs of personalisation on the basis of the traditional mass production method to better meet the market.

\subsection{The development of the manufacturing industry relies more on the informationization of the whole industry chain}

Rapid changes in the social environment have put great pressure on industrial enterprises, and it is now necessary to adapt to the times and make use of the integrated raw materials, research and development achievements, as well as the supply chain systems, in order to give full play to the real value of industrial manufacturing enterprises. From low to high, the integration should be promoted step by step. While vigorously developing the manufacturing industry, design innovation integrates upstream and downstream resource allocation to provide customers with more valuable services.

\section{THE ROLE OF INFORMATION TECHNOLOGY IN THE SUSTAINABLE DEVELOPMENT OF CHINA'S MANUFACTURING INDUSTRY}

The global manufacturing industry is facing a new reshuffle and reorganization. To have an advantage in the new scenario, it is most important to have advanced technology and resources. Because of this, we need to take the development of advanced manufacturing technology as the high point and make full use of information technology to improve our core competitiveness.

\subsection{Information technology can strengthen high-tech industries and build a modern economic system}

High-tech industries are knowledge-intensive and technology-intensive industries, which are fully integrated with internet technology, and their value has unpredictable economic benefits and provides considerable social contributions to society.

\subsection{Information technology enhances the quality of production and services and the environmental benefits of the manufacturing industry}

In the era of data-based manufacturing, information exchange and transmission need to be synthesized and transformed by using information technology. The whole manufacturing process runs on its own. Therefore, information technology is a necessary and essential factor for the intelligent development of the manufacturing industry.

Data and intelligence-based manufacturing can make use of the simulation experiments made by the computer to better allow the technical research and development personnel to carry out more adequate experimental debugging and other tests, so that the production staff can understand the products produced more directly and clearly, and greatly improve the production efficiency and reduce waste and pollution.

In addition, the pressure of resource, environment and labor cost of China's manufacturing is gradually increasing, and the manufacturing industry must be transformed and upgraded by information technology. Market demand is not only limited to the use of a product, but also focuses on post-use tracking service, maintenance, repair, recycling and so on, which can significantly foster the green utilization of energy and resources.

\subsection{Information technology meets the growing demand for personalized products}

Confronting the growing personalized demand of consumers around the world, manufacturers must be able to quickly and flexibly customize their production, and the key to achieving this is a vast data resource. By collecting and analyzing data from the entire product life cycle, not only can consumer demand be immediately communicated to producers, but production lines can also rely on the flow of data to make flexible 
production adjustments. In this way, from the Internet to big data, and then to mass customization can be realized. The cost of customization is significantly reduced, and the efficiency of production factors and resources is greatly improved.

\section{PROBLEMS OF INFORMATION TECHNOLOGY IN PROMOTING THE SUSTAINABLE DEVELOPMENT OF CHINA'S MANUFACTURING INDUSTRY}

The integration of contemporary information technology with the manufacturing industry is in line with China's market development and the needs of international manufacturing, but due to the deep integration of manufacturing and information technology is a brand new process, the task we face is still arduous in the long run.

\subsection{Resource information products are lack of integration}

The main reasons for the long cycle and high cost of manufacturing information digitization are the difficulty of data collection, changing demands, and unscientific and unclear means of implementation, etc. At present, many existing digital software products are relatively designed and implemented based on the fact that different businesses are divided into isolated systems. The data of the divided systems cannot be shared, integrated and unified, which is a waste of human, material and financial resources with a high risk.

\subsection{The development and application mode is simple and homogeneous}

Internet platforms of manufacturing enterprises have not been built yet, which greatly restricts the joint innovation of the Internet and the manufacturing industry. In addition, the core technology is also the biggest obstacle to the diversified and sustainable development of the manufacturing industry. Difficulties bring higher construction costs, which are daunting to manufacturers, resulting in the majority of companies still simply using supply chain software and relying mainly on human resources for operations and sales, and only using the network to complete some file transfer tasks. The efficient way of working on the internet is not even popular yet, and the low level of automation technology and the weak system integration ability lead to homogenization and simplification.

\subsection{Information technology is embedded in generalities and poorly managed}

First of all, the promotion of information technology on the manufacturing industry lacks the refinement and applicability of management, and it is difficult to realize the transformation and innovation of management. Secondly, enterprise informatization is a long-term systematic project. The standardization of employee information technology application level and enterprise management level is an important foundation of informatization. However, many manufacturing companies have problems such as low data standardization and basicization, and data management lacks uniqueness, completeness, accuracy and timeliness. Many enterprise informatization failures are caused by project implementation or application management, which are difficult to adapt to the specific requirements of the digital enterprise operation mode.

\subsection{Information technology has a low ability to promote manufacturing innovation and lacks core technology}

Due to technical bottleneck constraints, weak technical force, few types of intelligent products, slow absorption of information technology, equipment only stays in use. There is no more efficient utilization research, but simply meets immediate needs. We should make use of information technology to break through from the middle and low end of the value chains, own core technologies, key technologies and intellectual property rights, and take the environment-friendly path of leaping to the high-end of the manufacturing industry.

\section{COUNTERMEASURES OF INFORMATION TECHNOLOGY IN PROMOTING SUSTAINABLE DEVELOPMENT OF MANUFACTURING INDUSTRY}

\subsection{Providing resource and environment allocation for the convergence innovation of the information technology and manufacturing industry}

The crucial point to the sustainable development of the manufacturing industry is innovation. But at the initial stage, whether it is imitation, integrated innovation or cooperation innovation, it needs to be equipped with the appropriate configuration and corresponding resource investment. Therefore, in order to obtain greater profits and innovation capacity, we should invest tangible and intangible resources to strengthen the monitoring of market demand information of manufacturing products and provide efficient information tracking research and development for each manufacturing industry. It is necessary to build a resource sharing platform between departments to achieve the most efficient dissemination and utilization of information resources, thus saving resources and 
improving the sustainability and efficiency of the manufacturing industry.

\subsection{Strengthening demonstration, guidance and promotion}

First of all, we need to select the target market, properly deploy the publicity and resource personnel, and put the exemplary benchmarking enterprises in place in order to achieve demonstrative effects. It is in sharp contrast with the traditional manufacturing products before. This will guide consumers and manufacturers in the same industry and gradually improve manufacturing, sales and after-sales service in the acceleration of informationization, and realize demonstration and promotion.

\subsection{Consolidating carrier construction and factor guarantee, and striving to cultivating professional technical talents}

In the research and development of technological innovation in the industry, we should firstly clarify the corresponding responsibilities of each post, control the cost and time of innovation, and encourage talents' innovation requirements. Secondly, it is necessary to arrange corresponding training for innovative talents so that they can actively adapt to and participate in the innovation process. Finally, the corresponding salary and promotion system should be established to encourage the positive attitude and initiative of talent innovation.

In summary, we should focus on the quantity and quality of research and development personnel investment, actively introduce various kinds of excellent professional and technical talents through training, recruitment, transfer and so on, increase the number of enterprise research and development personnel and promote the personnel selection, so as to establish a high-quality research and development team in the industry and provide talent guarantee for the implementation of technological innovation.

\subsection{Reinforcing the control during the implementation of technological innovation}

A project or the birth of a new product must be based on strict control of the time, which must be strictly controlled in the production and development cycle, including the time of external demand, research, development and creation time, processing and manufacturing time and delivery time, etc. Effective control and monitoring of a project's innovation time can better control the financial and material investment and reduce unnecessary waste in time, thus improving efficiency and the overall level of the industry.

\section{CONCLUSION}

The implementation of technological innovation in manufacturing enterprises cannot be separated from high technology and innovative processes. In technological innovation, advanced knowledge resource input is an important carrier and crucial element to promote innovation integration. Talent is the core resource for implementing technological innovation and the key element in the process of promoting the sustainable development of the manufacturing industry. It is the center to master new technology, develop new products, apply new knowledge and information, and promote and perfect the implementation of technological innovation mode.

From the perspective of sustainable development, the key to contemporary information technology in advancing the evolution and development of manufacturing is inter-firm value creation, transmission and acquisition. Through the application of information technology and scientific and technological means, traditional manufacturing industry can improve production efficiency, reduce resource waste and optimize the environment. Information technology, as the cornerstone of the sustainable development of the manufacturing industry, will provide strong support for China's high-tech industry, realize a win-win situation for all parties and build China into a real information-based manufacturing powerhouse.

\section{REFERENCES}

[1] M. Abu-Bakr, A. Abbas, I. Tomaz, M. S. Soliman, M. Luqman, H. Hegab, Sustainable and Smart Manufacturing: An Integrated Approach, Sustainability 12(6) (2020) 1-19.

[2] L. Barreto, A. Amaral, T. Pereira, Industry 4.0 implications in logistics: an overview, Procedia Manufacturing 13 (2017) 1245-1252.

[3] C.B. Joung, J. Carrell, P. Sarkar, S.C. Feng, Categorization of indicators for sustainable manufacturing, Ecological Indicators 24 (2013) 148-157.

[4] G. Prause, Sustainable business models and structures for industry 4.0, Journal of Security and Sustainability Issues 5(2) (2015) 159-169. 